\title{
EDITORIAL
}

\section{AGRICULTURA SUSTENTABLE}

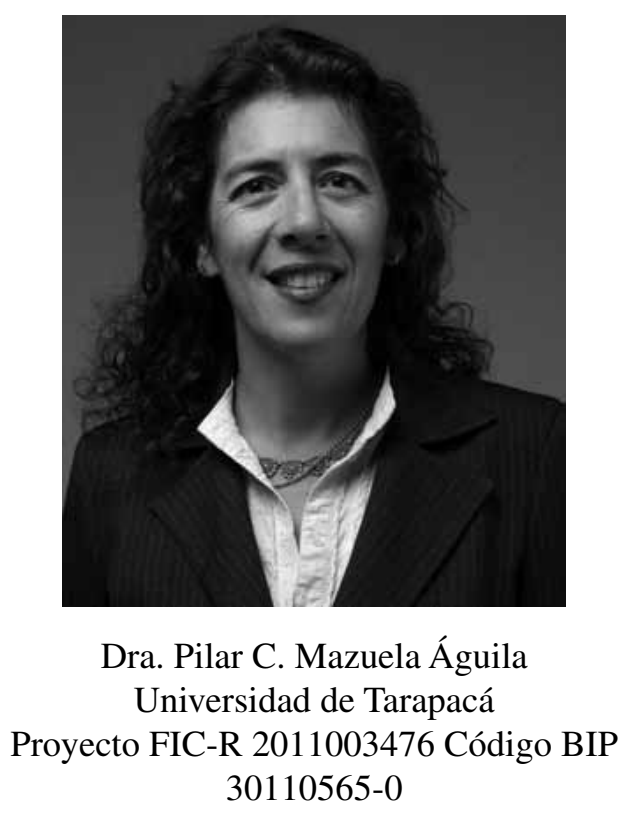

A fines de los años 90, la provincia de Arica estaba en pleno proceso de erradicación de la mosca de la fruta (Ceratitis capitata), condición fundamental para que los exportadores de fruta de Chile pudieran acceder a nuevos mercados, especialmente asiáticos. Hacia el año 2003, el Servicio Agrícola y Ganadero autorizó que los productores de tomate que cultivaran bajo malla anti áfidos, previamente supervisados por el SAG, no sometieran sus tomates a la fumigación para el control de esta plaga. La diferencia en calidad del producto puesto en Santiago incentivó a que productores mas arriesgados aumentaran la superficie bajo malla. En diciembre del 2004 la provincia de Arica fue declarada libre de la mosca de la fruta. Esto permitió que el país fuese reconocido libre de Ceratitis capitata por Estados Unidos el año 2010. La existencia de incentivos como la Bonificación a la Inversión Zonas Extremas; Crédito Tributario a la Inversión en Activo Fijo y Bonificación a la Contratación de Mano de Obra que se han focalizado en la agricultura de alta tecnología para mantener la competitividad del sector más la creación de la Región de Arica y Parinacota en octubre del 2007, dio el impulso final a la consolidación de la actividad agrícola, como un eje de desarrollo de la nueva Región.

\section{El clima}

Los valles costeros de la XV Región presentan condiciones climáticas excepcionales para el cultivo de hortalizas durante todo el año, siendo el principal proveedor de hortalizas de la zona Central durante el invierno. Predominan las condiciones de clima de desierto costero con nubosidad abundante, ausencia de heladas, vientos moderados, alta humedad relativa y alta radiación solar directa, durante todo el año. La temperatura media anual es de $18{ }^{\circ} \mathrm{C}$, máximas medias anuales de $23,6{ }^{\circ} \mathrm{C}$ y mínimas de $13,8{ }^{\circ} \mathrm{C}$. Pese a que el clima benigno permite la producción de hortalizas durante todo el año, para los agricultores no es atractivo producir durante el verano principalmente por el menor precio que obtienen por sus productos y mayor costo de producción en fitosanitarios y transporte comparados con los costos de la zona central.

\section{Superficie destinada a hortalizas}

La región cuenta con una superficie total de 2.877 ha cultivadas con hortalizas, desglosadas en 2.854 ha al aire libre y 24 ha bajo invernadero (INE, 2007). El tomate para consumo fresco supera las $840 \mathrm{ha}$; le sigue el poroto verde y pimiento con 171 y 138 ha, respectivamente (INE, 2007). Los rendimientos medios superan significativamente las medias nacionales, alcanzando medias de $113 \mathrm{tha}^{-1}$ en tomate; $46,5 \mathrm{t} \mathrm{ha}^{-1}$ en pimiento $\mathrm{y}, 9,8 \mathrm{tha}^{-1}$ en 
poroto verde respecto a la media nacional de 71 , 37 y 8,4 t ha $^{-1}$, respectivamente (INE, 2010). Otras hortalizas de importancia económica son el choclo, con 958 ha, seguida por la cebolla que suma un total de 342 ha, considerando la cebolla temprana (264 ha) y la de guarda (78 ha). Los rendimientos medios son de 44.060 unidades de choclo y $30 \mathrm{t}$ de cebolla, menor que la media nacional que alcanza 46.420 unidades de choclos y $48 \mathrm{t} \mathrm{ha}^{-1}$ de cebolla.

De estas hortalizas, el tomate es el cultivo de mayor importancia en la economía regional, debido a la superficie cultivada, la intensificación cultural y su efecto en el empleo directo y el indirecto, este último vinculado principalmente a la industria anexa, como venta de insumos, asesorías técnicas, embalaje y transporte. Algunos productores con mayor capacidad empresarial han hecho innovaciones en los procesos de producción para mejorar la eficiencia en el uso de agua, fertilizantes y uso de pesticidas con mejor tecnología en el fertirriego y en los sistemas de protección del cultivo.

\section{Agricultura y medio ambiente}

Hoy no se entiende un cultivo y su producción desligados de las consideraciones medio ambientales y sus efectos sobre la salud de consumidores y productores. Es común utilizar una serie de términos descriptivos o indicativos de una normativa o "etiqueta" que regula los procesos de producción y comercialización. Como ejemplo de estos términos cada vez más familiares para el horticultor que quiere ser competitivo tenemos: cultivo ecológico, cultivo biológico, agricultura sostenible, sustentable, agricultura no contaminante y amigable con el medio ambiente, producción controlada, producción integrada, etc. Todos ellos tienen de común un intento de racionalizar la producción con mayor o menor grado de exigencia y limitaciones en el sistema productivo.

Con la exigencia de los consumidores por el cuidado del medio ambiente se han generado una serie de normativas que obligan a la producción sostenible. Sin embargo, la sustentabilidad de una agricultura de zonas áridas esta muy vinculada a la viabilidad económica, pues si un agricultor no tiene la rentabilidad esperada a su esfuerzo puede reestructurar o abandonar la actividad agrícola. Esto requiere del desarrollo de nuevas tecnologías e instrumentos de medición para la optimización de los recursos naturales que genere un buen resultado económico (mejorando la productividad y la rentabilidad); procesos de producción estandarizados y certificados; el desarrollo de una industria anexa (insumo, transporte, servicios) y mejores estrategias de comercialización (marca, denominación de origen, alimentos funcionales).

La creciente habilitación de superficie cultivada, la menor disponibilidad de agua para el riego y la progresiva exigencia en calidad y sanidad de las hortalizas, especialmente las de consumo en fresco, demandan la búsqueda constante de alternativas que potencien el desarrollo productivo. Esto puede medirse a través de indicadores de sustentabilidad de la actividad hortícola frente a situaciones de diversificación productiva que ofrezca mejor alternativa a los agricultores para mantener la competitividad del sector frente a otras zonas productoras como Limache, Quillota, Ovalle. Estos indicadores son una herramienta para la toma de decisiones respecto a:

1. Proponer una generación de políticas públicas para dar sustentabilidad a la actividad hortícola regional.

2. Actualizar los instrumentos vigentes para el incentivo de tecnologías que mejoren la competitividad del sector hortícola.

\section{Indicadores de sustentabilidad}

A partir del informe Brundtland, el mundo es concebido como un sistema global donde se considera el concepto de desarrollo sostenible como un proceso multidimensional que afecta al sistema económico, social y medioambiental. De esta forma, la sustentabilidad se convierte en una variable a tener en cuenta en las decisiones de política económica. Sin embargo, una de los aspectos más preocupantes ha sido el conocer si realmente se siguen pautas de sustentabilidad, es decir, si se tienen indicadores que nos alerten sobre la evolución positiva o negativa del proceso. Al hacer una revisión de los indicadores que se han ido desarrollando se ha llegado a la conclusión de que el desarrollo sostenible sigue constituyendo una de las actividades de mayor importancia para las economías. Esta información debe ser construida en forma sistemática, fiable y con criterios homogéneos que permita la comparación entre regiones y países, sin olvidar que, al hablar del desarrollo sostenible, hay que hacer mención a nuestra propia geografía en un ambiente semiárido, y realidades económicas, ecológicas 
y sociales muy diferentes al resto del país y, por tanto, necesidades muy distintas. La sustentabilidad de la actividad agrícola permite: mayor inversión pública vinculada a mejorar la competitividad de la agricultura; fomentar la inversión vía cuantificación de la rentabilidad; favorecer la instalación de nuevas tecnologías y generar información para facilitar el emprendimiento producto de conocer las áreas más rentables en la actividad agrícola regional o potencialmente desarrollables tanto económica como socialmente. La suscripción de convenios internacionales y certificaciones como ChileGAP nos obligan a mejorar los procesos productivos que garanticen la inocuidad de los productos, el cuidado del medio ambiente y la salud de consumidores y productores, así como el respeto a las condiciones laborales de los trabajadores agrícolas.

\section{Referencias}

Instituto Nacional de Estadísticas (2007) VII Censo Agropecuario y Forestal 2006-2007. Resultados preliminares. INE Ediciones, Santiago de Chile, $444 \mathrm{p}$.

Instituto Nacional de Estadísticas (2010) Información Hortícola. Publicación Especial 2008-2009. INE Ediciones, Santiago de Chile, $128 \mathrm{p}$. 